\title{
The Global Epidemic of Atherosclerotic Cardiovascular Disease
}

\author{
Salim Yusuf Stephanie Ôunpuu Sonia Anand \\ Population Health Research Institute and Division of Cardiology, McMaster University, Hamilton, Ont., Canada
}

\begin{abstract}
Of the 50 million deaths that occur in the world, 40 million occur in developing countries. Already a substantial proportion of these deaths are due to cardiovascular diseases. It is projected that by the year 2025 well over $80-$ $90 \%$ of all the cardiovascular diseases in the world will be occurring in low income and middle income countries. This increase in cardiovascular disease is due to a number of causes which include the following: (1) conquest of deaths in childhood and infancy from nutritional deficiencies and infection; (2) urbanization with increasing levels of obesity; (3) increasing longevity of the population so that a higher proportion of individuals reach the age when they are subject to chronic diseases, and (4) increasing use of tobacco worldwide. In most countries in the world other than those in the West, the burden of disease is still due to a combination of infections and nutritional disorders as well as those due to chronic diseases. This double burden of disease poses a challenge that is not only medical and epidemiological, but also social and political. Tackling this projected global epidemic of cardiovascular disease therefore needs policies that combine sound knowledge of prevention, good clinical care, but also deals with the allocation of resources for both individual level and community level preventive strategies. The former involves dealing with high-risk individuals through appropriate medical and therapeutic interventions. The latter involves societal level changes including laws that curb the use of tobacco, and strategies that promote physical activities, and appropriate nutrition.
\end{abstract}

Copyright $@ 2002$ S. Karger AG, Basel

\section{Introduction}

The last century has witnessed the most dramatic improvements in health for most populations. During this period, life expectancy at birth has increased by an average of over 25 years. The health status and dominant disease profile of human societies have historically been linked to the level of their economic development and social organization. With industrialization, the major causes of death and disability, in the more advanced societies, have shifted from a predominance of nutritional deficiencies and infectious diseases, to chronic diseases such as cardiovascular disease (CVD), cancer and diabetes. This shift from a dominance of the acute communicable diseases to the chronic degenerative diseases, has been termed 'the epidemiologic transition' [1]. At any given time, different countries of the world or even different regions within a country are at different stages of the epidemiologic transition. This transition occurs between different disease categories (e.g. deaths from childhood diarrhea and malnutrition giving way to adult chronic diseases), and also within specific disease categories (e.g. across different CVD, rheumatic heart disease of the young giving way to chronic arterial diseases of middle age or valve calcification, degeneration and heart failure of the elderly). The epidemiologic transition can at times shift back when dramatic changes in social and economic conditions occur resulting in a resurgence of diseases of poverty and infections (e.g. in the last 10 years in Russia, life expectancy has shortened and there has been an
Salim Yusuf, DPhil, FRCP

2nd Floor McMaster Clinic, Hamilton General Hospital

237 Barton Street East, Hamilton, Ont. L8L 2X2 (Canada)

Tel +1 905527 7327, Fax +19055211166

E-Mailyusufs@fhs.mcmaster.ca 
Table 1. Modified model of the stages of epidemiologic transition as it pertains to cardiovascular diseases

\begin{tabular}{lllll}
\hline Stages of development & $\begin{array}{l}\text { Deaths from } \\
\text { CVD, \% of } \\
\text { total deaths }\end{array}$ & Predominant CVDs & Regional examples \\
\hline 1 Age of pestilence and famine & $5-10$ & $\begin{array}{l}\text { Rheumatic heart disease, infectious, and } \\
\text { nutritional cardiomyopathies }\end{array}$ & $\begin{array}{l}\text { Sub-Saharan Africa, rural India, } \\
\text { and South America }\end{array}$ \\
\hline 2 Age of receding pandemics & $10-35$ & $\begin{array}{l}\text { As above + hypertensive heart disease and } \\
\text { hemorrhagic strokes }\end{array}$ & China \\
\hline 3 Age of degenerative and & $35-55$ & $\begin{array}{l}\text { All forms of strokes, ischemic heart disease at } \\
\text { young ages, increasing obesity and diabetes }\end{array}$ & $\begin{array}{l}\text { Urban India, former socialist } \\
\text { economies, aboriginal } \\
\text { communities }\end{array}$ \\
\hline $\begin{array}{l}\text { Age of delayed degenerative } \\
\text { diseases }\end{array}$ & $<50$ & Stroke and ischemic heart disease at old age & $\begin{array}{l}\text { Western Europe, North America, } \\
\text { Australia, New Zealand }\end{array}$ \\
\hline 5 Age of health regression and \\
social upheaval
\end{tabular}

During stages 1-4, life expectancy increases, whereas in stage 5 life expectancy decreases compared to stages 4 and even 3 .

Table 2. Contribution of noncommunicable diseases and various individual diseases to the global mortality and global burden of disease in 1998, subdivided by low income countries and middle income countries

\begin{tabular}{lllll}
\hline Disease category & $\begin{array}{l}\text { Contribution to } \\
\text { total global } \\
\text { mortality, } \%\end{array}$ & $\begin{array}{l}\text { Contribution to } \\
\text { total burden of } \\
\text { disease, } \%\end{array}$ & $\begin{array}{l}\text { LIC + MIC } \\
\text { contribution to } \\
\text { global NCD } \\
\text { mortality, } \%\end{array}$ & $\begin{array}{l}\text { LIC + MIC } \\
\text { contribution to } \\
\text { global NCD } \\
\text { burden, \% }\end{array}$ \\
\hline Total NCD & 58.8 & 43.0 & 77 & 85 \\
Total CVD & 30.9 & 10.3 & 78 & 86.3 \\
Total cancers & 13.4 & 5.8 & 72 & 79 \\
Diabetes & 1.1 & 0.8 & 73 & 73 \\
COPD & 4.1 & 2.0 & 87.5 & 91.4 \\
\hline
\end{tabular}

LIC = Low income country; $\mathrm{MIC}=$ middle income country; $\mathrm{NCD}=$ noncommunicable disease COPD = chronic obstructive pulmonary disease.

Source: Derived from estimates provided in World Health Report 1999. increase in infectious diseases). Therefore, the epidemiologic transition is both global and regional, within and across diseases and is potentially reversible. Table 1 provides a schema of the epidemiologic transition as it relates to CVD.

During the past 30 years, large declines in death rates due to CVD have been experienced in several Western countries, whereas substantial increases have been experienced in developing countries. These contrasting trends are expected to continue. Over the next three decades, premature morbidity and mortality attributable to CVD will almost double globally from 85 million disability- adjusted life years (DALY) in 1990, to $140-160$ million DALY in 2020 , with about $80 \%$ of this burden occurring in developing countries [2,3] (table 2). Other than subSaharan Africa, all geographic regions are already experiencing substantial disease burden from ischemic heart disease (IHD) (table 3) and can anticipate substantial increases in mortality rates over the next decade. 
Table 3. Estimates of AMI mortality rates (per 100,000) by region ${ }^{1}$ and gender (all ages) [2]

\begin{tabular}{|c|c|c|c|c|c|c|}
\hline \multirow[t]{2}{*}{ Region } & \multicolumn{2}{|l|}{ Men } & \multicolumn{2}{|c|}{ Women } & \multicolumn{2}{|c|}{$\%$ increase } \\
\hline & 1990 & 2000 & 1990 & 2000 & men & women \\
\hline EME & 212 & 228 & 206 & 210 & +8 & +2 \\
\hline FSE & 283 & 372 & 309 & 363 & +32 & +18 \\
\hline India & 141 & 166 & 136 & 154 & +18 & +16 \\
\hline China & 66 & 80 & 69 & 75 & +21 & +9 \\
\hline OAI & 68 & 82 & 67 & 77 & +21 & +15 \\
\hline SSA & 36 & 36 & 45 & 43 & 0 & -4 \\
\hline LAC & 81 & 95 & 76 & 87 & +17 & +14 \\
\hline MEC & 124 & 139 & 118 & 124 & +12 & +5 \\
\hline Total world & 118 & 133 & 120 & 127 & +13 & +6 \\
\hline
\end{tabular}

$1 \quad$ EME = Established market economies; FSE = former socialist economies of Europe; OAI = other Asia and Islands; SSA = SubSaharan Africa; LAC = Latin American countries; MEC = Middle Eastern Crescent.

\section{Reasons for Increases in Cardiovascular Diseases}

The expected increases in CVD in developing countries are probably a result of at least three contributing factors: First, decreasing mortality from acute infectious diseases and increases in life expectancy will result in a higher proportion of individuals reaching middle and old age. Second, lifestyle and socioeconomic changes associated with urbanization in developing nations will lead to higher levels of risk factors for CVD. Third, special susceptibility of certain populations (e.g. due to specific genes) may lead to a greater impact on clinical events compared to Western populations.

The rates projected in table 3 are based solely upon demographic changes. If the prevalence of various CVD risk factors also rise as a consequence of adverse lifestyle changes accompanying industrialization and urbanization, the rates of CVD mortality and morbidity could rise even higher than the projected rates. Further, both the degree and the duration of exposure to the CVD risk factors would increase as a result of higher risk factor levels coupled with a longer life expectancy. Higher prevalence of both risk factors for CVD and disease rates in urban compared to rural communities in India $[4,5]$ and China [6] provide evidence of these trends.

Lifestyle changes observed in countries undergoing transition include changes in diet, physical activity and tobacco use. The globalization of food production and marketing has resulted in greatly increased availability of cheap vegetable oils and fats, and increased consumption of energy-dense foods which may be poor in dietary fiber and several micronutrients $[7,8]$. Other characteristics of this nutrition transition include a shift from plant to animal protein, and shifts towards refined carbohydrates and sweets, and increased prevalence of obesity. This transition now occurs even in countries and groups with a relatively low level of income, and is further accelerated by urbanization. In South Africa for example, length of time living in an urban environment has been directly associated with increased dietary fat and decreased carbohydrate consumption, and a shift from plant to animal sources of protein [7]. National nutrition surveys conducted in Brazil during 1974/75 and 1989 have demonstrated both a striking increase in the prevalence of overweight and obesity (from $21 \%$ of the population in $1974 / 75$ to $33 \%$ in 1989), and that overweight/obesity is positively associated with income and urban residence [9]. Data from the China Health and Nutrition Surveys in eight Chinese provinces indicate that between 1989 and 1991, the prevalence of relatively high fat consumption was increased among adults living in urban areas and among higher income groups. For example in urban areas, $46 \%$ of high income participants, $38 \%$ of middle income participants and $20 \%$ of low income participants consumed $>30 \%$ energy as fat, compared to 25,19 and $14 \%$ of high, middle and low income participants in rural areas [7]. Differences were also observed in activity patterns. From 1989 to 1991 , the prevalence of sedentary activity patterns increased substantially among urban residents in all income groups, a trend not observed among rural residents. Over the same time period, an increased prevalence of overweight was observed in the high and middle income groups but not in the low income group [10].

Smoking rates vary widely by geographic region and gender, and trends towards increased tobacco consumption in most 'transitional' countries contrast with the decreases observed in most industrialized nations. Increased tobacco smoking in the former socialist economies (FSE), Latin America, Middle East Crescent, India and China will lead to large increases in chronic disease mortality attributable to tobacco. For example, mortality in India that is attributable to tobacco will rise from $1 \%$ in 1990 to $13 \%$ in 2020 . In the FSE, mortality attributable to tobacco will rise from 14 to $23 \%$ in the same time period [11]. It is estimated that by 2025 , tobacco-attributable deaths in China will be a staggering 2 million annually [12]. 
Fig. 1. Prevalence of CVD for given levels of

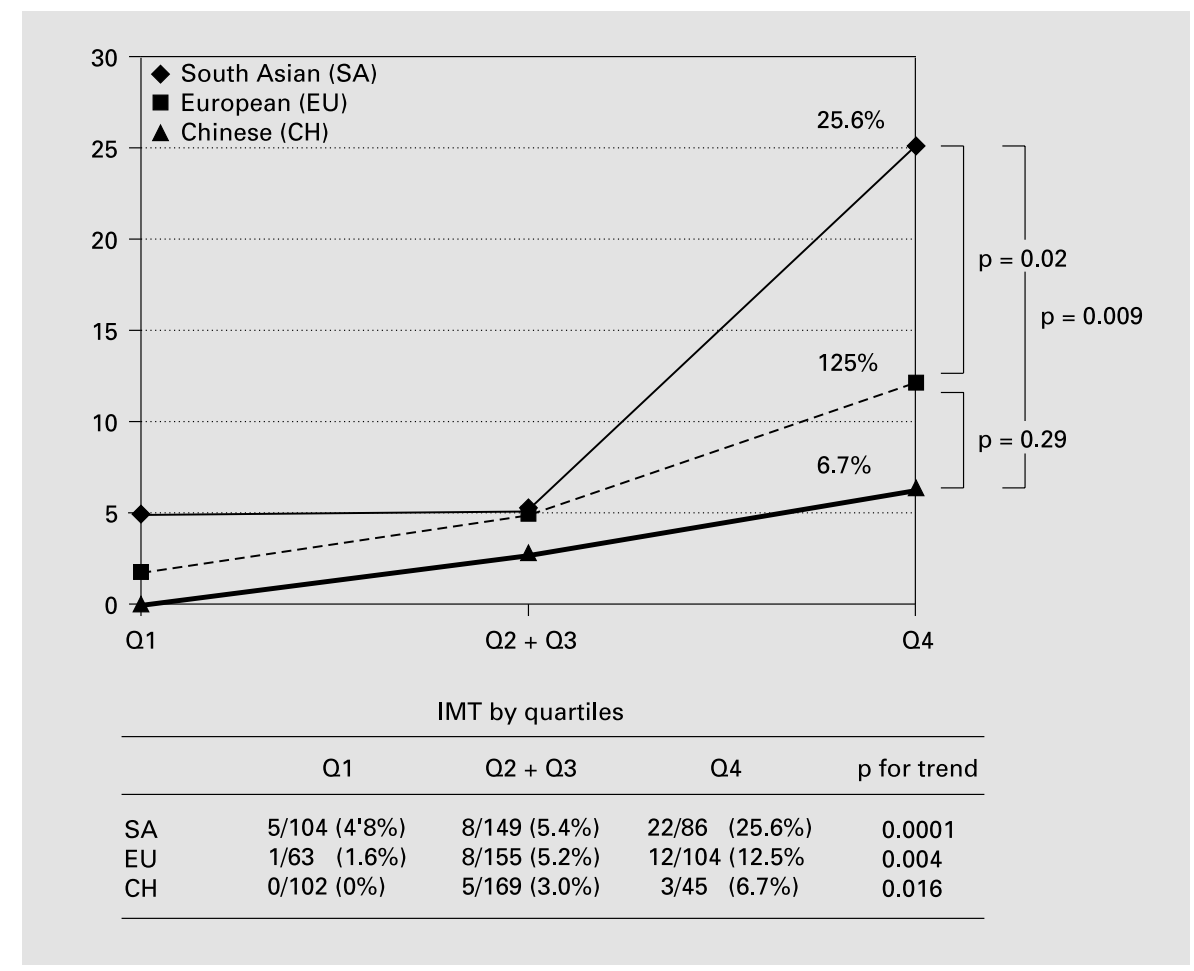
carotid atherosclerosis.

The metabolic response to these altered CVD risk profiles may vary in specific populations. One such hypothesis has been referred to as the 'thrifty gene hypothesis', which describes a process of selective survival, where a population was occasionally exposed to adverse environmental conditions and associated famine [13]. For example, selection of a gene that increases the efficiency of fat storage through an oversecretion of insulin in response to a meal, would favor survival in a period of famine. However, a high level of energy intake (because of the relatively easy access to 'rich' foods) with urbanization may lead to a less desirable response that includes obesity, hyperinsulinemia, diabetes and atherosclerosis. Such gene-environment interactions may relate to higher blood pressure levels (e.g. salt retention or sensitivity genes), or higher homocysteine levels (due to higher consumption of meats and lower consumption of vegetables interacting with various genes that affect homocysteine synthesis or break down).

Studies from Canada, United Kingdom, Singapore, South Africa and Mauritius have consistently demonstrated very high rates of coronary heart disease (CHD) among individuals of South Asian origin, intermediate rates among those of European origin with the lowest rates among those of African or Chinese origin [4-6, 14,
15]. However, the extent to which these variations in CHD by ethnicity are due to genetic factors or environmental factors remains unclear. Recent studies have identified candidate genes that may correlate with CVD and with its risk factors such as obesity, plasma lipoproteins, elevated blood pressure and elevated blood glucose [1619]. The relative frequencies of various genes among different ethnic groups is not known. An assessment of the relevance of varying gene frequencies or expression that may ultimately lead to differences in CVD between populations must also incorporate information on a host of environmental factors such as lifestyle or nutritional and possible programming factors [20].

\section{Ongoing Studies}

In order to overcome some of the limitations of the currently available data and to obtain standardized information across ethnic groups both within and across many different countries, we have been involved in facilitating three studies. First, Study of Health Assessment and Risk in Ethnic groups (SHARE) explores the relationship of environmental (nutrition, tobacco use, lifestyle and psychosocial factors) and genetic factors, as well as subclini- 


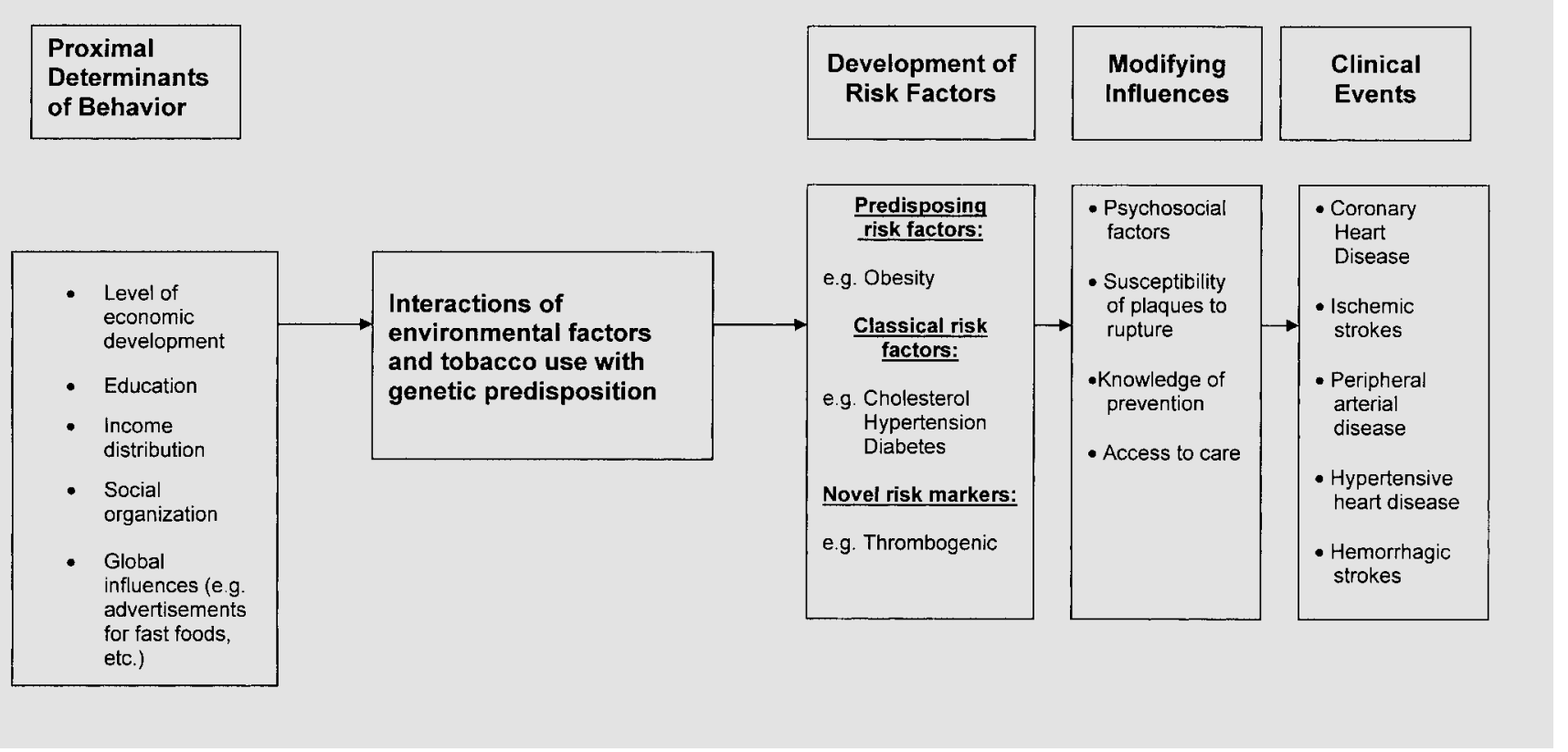

Fig. 2. Schema for societal level 'pathway' for the development of atherothrombotic cardiovascular diseases.

cal atherosclerosis, in about 1,300 individuals from four Canadian groups (Canadians of European, South Asian, Chinese and Aboriginal descent) [14]. An initial report indicates that, as expected, South Asians had the highest rates of CVD followed by Europeans and then the Chinese. However, the degree of atherosclerosis (measured utilizing B-mode carotid ultrasonography) was the highest among Europeans but significantly lower rates in South Asians and Chinese (with only a modest difference among these two latter groups). Although the degree of carotid atherosclerosis correlated with the prevalence of clinical events, for any given level of atherosclerosis, South Asians had significantly higher rates of cardiovascular events than the other ethnic groups. This suggests that the propensity to plaque rupture or thrombosis, leading to clinical events, may vary by ethnic group (fig. 1). The classical risk factors (lipids, glucose abnormalities, blood pressure and tobacco use) did correlate with clinical events with some emerging risk factors (e.g. elevated levels of plasminogen activator inhibitor-1 and lipoprotein (a)), also adding predictive information. However, after inclusion of all measured risk factors and degree of atherosclerosis, South Asian ethnicity conferred additional risk. This suggests that some additional factor(s) that are yet unidentified are of importance among South Asians. By contrast, the lower rates of CVD among Chinese compared to the Europeans were entirely explained by the risk factors and atherosclerosis, indicating that if Chinese adopt Western lifestyles, their rates of CVD will tend to approximate those observed in European populations.

In a second study, a group of scientists are collaborating in a large international, multicenter, hospital-based incident case-control study (INTER-HEART). Approximately 12,000 incident cases of acute myocardial infarction in men and women admitted to the coronary care unit, and a similar number of hospital-based controls matched by age and gender, are expected to be enrolled over the next 3-4 years from about 50 countries. Women are expected to comprise about $25 \%$ of all participants. The majority of subjects will be recruited from the Middle East, South Asia, Southeast Asia, China, Eastern Europe, Russia, and Latin America with significant numbers from Africa, North America and Western Europe. These studies are initial steps towards exploring the causes of CVD in different populations across the world. In addition to exploring the importance of known and emerging risk factors for CVD, INTER-HEART will assess if the impact of these risk factors varies by region or ethnicity. The findings will undoubtedly have to be explored in further detail in large prospective cohort studies that combine a range of 
methodologies (e.g. proximal societal level determinants, plus individual level information on nutrition, lifestyle factors, biological markers as well as genetic variations) in several of the participating countries (fig. 2). Such studies are already being initiated in several developing countries (e.g. the Prospective Urban-Rural Epidemiologic Study in South India involving 5,000 urban residents and 5,000 rural residents). Similar studies in different parts of the world will provide valuable information upon which a global strategy for CVD prevention can be developed that is both ethnically and regionally sensitive [21].

\section{Acknowledgements}

Salim Yusuf holds a Heart and Stroke Foundation of Ontario Chair in Cardiovascular Research and is a Senior Scientist of the Canadian Institutes of Health Research (CIHR). Stephanie Ônpuu is a CIHR Senior Research Fellow. Sonia Anand is a recipient of a CIHR Clinician Scientist Award.

\section{References}

1 Omran AR: The epidemiologic transition: A theory of the epidemiology of population change. Millbank Memorial Fund Q 1971;49: 509-538.

2 Murray CJ, Lopez AD: The Global Burden of Disease: A Comprehensive Assessment of Mortality and Disability from Disease, Injuries and Risk Factors in 1990 and Projected to 2020. Boston, Harvard School of Health, 1996.

3 Murray CJ: Quantifying the burden of disease: The technical basis for disability-adjusted life years. Bull WHO 1994;72:429-445.

4 Gupta R, Prakash H, Kaul V: Cholesterol lipoproteins, rural-urban differences and prevalence of dyslipidaemia among males in Rajasthan. JAPI 1997;45:275-279.

5 Gupta R, Gupta VP: Meta-analysis of coronary heart disease prevalence in India. Indian Heart J 1996;48:241-245.

6 People's Republic of China-United States Cardiovascular and Cardiopulmonary Epidemiology Research Group: An epidemiological study of cardiovascular and cardiopulmonary disease risk factors in four populations in the People's Republic of China. Circulation 1992;85:10831096.

7 Drewnoski A, Popkin BM: The nutrition transition: New trends in the global diet. Nutr Rev 1997;55:31-43.

8 Lang T: The public health impact of globalisation of food trade; in Shetty PS, McPherson K (eds): Diet, Nutrition and Chronic Disease: Lessons from Contrasting Worlds. Chichester, Wiley 1997, pp 173-187.
9 Sichieri R, Coitinho DC, Leao MM, Recine E, Everhart JE: High temporal, geographic, and income variation in body mass index among adults in Brazil. Am J Public Health 1994;84: 793-798.

10 Popkin BM, Paeratakul S, Ge K, Fengying Z: Body weight patterns among the Chinese: Results from the 1989 and 1991 China Health and Nutrition Survey. Am J Public Health 1995;85: 690-694.

11 World Health Organisation: Tobacco or Health: A Global Status Report. Geneva, World Health Organization, 1997.

12 Peto R: Tobacco-related deaths in China. Lancet $1987 ;$ ii: 211 .

13 Hales CN, Barker DJ: Thrifty genotype type 2 (non-insulin-dependent) diabetes mellitus: The thrifty phenotype hypothesis. Diabetologia 1992;35:595-601.

14 Anand SS, Yusuf S, Vuksan V, Devanesen S, Teo KK, Montague PA, Kelemen L, Yi Q, Lonn E, Gerstein H, Hegele RA, McQueen M, for the SHARE investigators: Differences in risk factors, atherosclerosis, and cardiovascular disease between ethnic groups in Canada: The Study of Health Assessment and Risk in Ethnic groups (SHARE). Lancet 2000;356:279-284.
15 Yusuf S, Reddy S, Ounpuu S, Anand S: Global burden of cardiovascular diseases. II. Variations in cardiovascular disease by specific ethnic groups and geographic regions and prevention strategies. Circulation 2001;104:28552864.

16 Dilley A, Austin H, Hooper WC, Lally C, Ribeiro MJA, Wenger NK, Silva V, Rawlins P Evatt B: Relation of three genetic traits to venous thrombosis in an African-American population. Am J Epidemiol 1998;147:30-35.

17 Hegele RA, Connelly PW, Hanley AJ, Sun F, Harris SB, Zinman B: Common genomic variation in the APOC3 promoter associated with variation in plasma lipoproteins. Arterioscler Thromb Vasc Biol 1997; 17:2753.

18 Hegele RA, Connelly PW, Scherer SW, Hanley AJ, Harris SB, Tsui LC, Zinman B: Paraoxonase-2 gene (PON2) G148 variant associated with elevated fasting plasma glucose in noninsulin-dependent diabetes mellitus. J Clin Endocrinol Metab 1997;82:3373-3377.

19 Hegele RA, Breckenridge WC, Brunt JH, Connelly PW: Genetic variation in factor VII associated with variation in plasma lipoprotein(a) concentration. Arterioscler Thromb Vasc Biol 1997; 17:1701-1706.

20 Reddy KS, Yusuf S: Emerging epidemic of CVD in the developing countries. Circulation 1997;97:596-601.

21 Howson CP, Reddy S, Ryan TJ, Bale JR (eds) Control of Cardiovascular Diseases in Developing Countries: Research, Development, and Institutional Strengthening. Washington, National Academy Press, 1998 